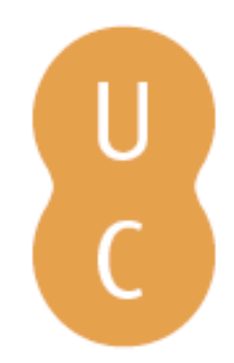

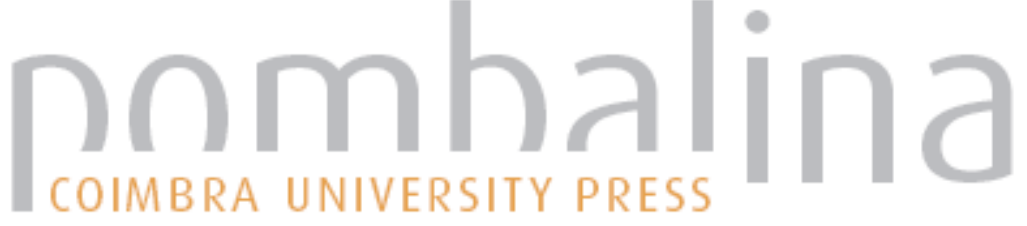

\section{Imunodeficiências Primárias: quando suspeitar?}

\author{
Autor(es): Lemos, Sónia
}

Publicado por: Imprensa da Universidade de Coimbra

URL

persistente: URI:http://hdl.handle.net/10316.2/43145

DOI: $\quad$ DOI:https://doi.org/10.14195/978-989-26-1300-0_44

Accessed : $\quad$ 26-Apr-2023 10:15:28

A navegação consulta e descarregamento dos títulos inseridos nas Bibliotecas Digitais UC Digitalis, UC Pombalina e UC Impactum, pressupõem a aceitação plena e sem reservas dos Termos e Condições de Uso destas Bibliotecas Digitais, disponíveis em https://digitalis.uc.pt/pt-pt/termos.

Conforme exposto nos referidos Termos e Condições de Uso, o descarregamento de títulos de acesso restrito requer uma licença válida de autorização devendo o utilizador aceder ao(s) documento(s) a partir de um endereço de IP da instituição detentora da supramencionada licença.

Ao utilizador é apenas permitido o descarregamento para uso pessoal, pelo que o emprego do(s) título(s) descarregado(s) para outro fim, designadamente comercial, carece de autorização do respetivo autor ou editor da obra.

Na medida em que todas as obras da UC Digitalis se encontram protegidas pelo Código do Direito de Autor e Direitos Conexos e demais legislação aplicável, toda a cópia, parcial ou total, deste documento, nos casos em que é legalmente admitida, deverá conter ou fazer-se acompanhar por este aviso.

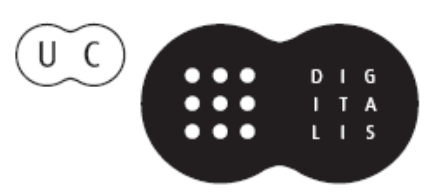




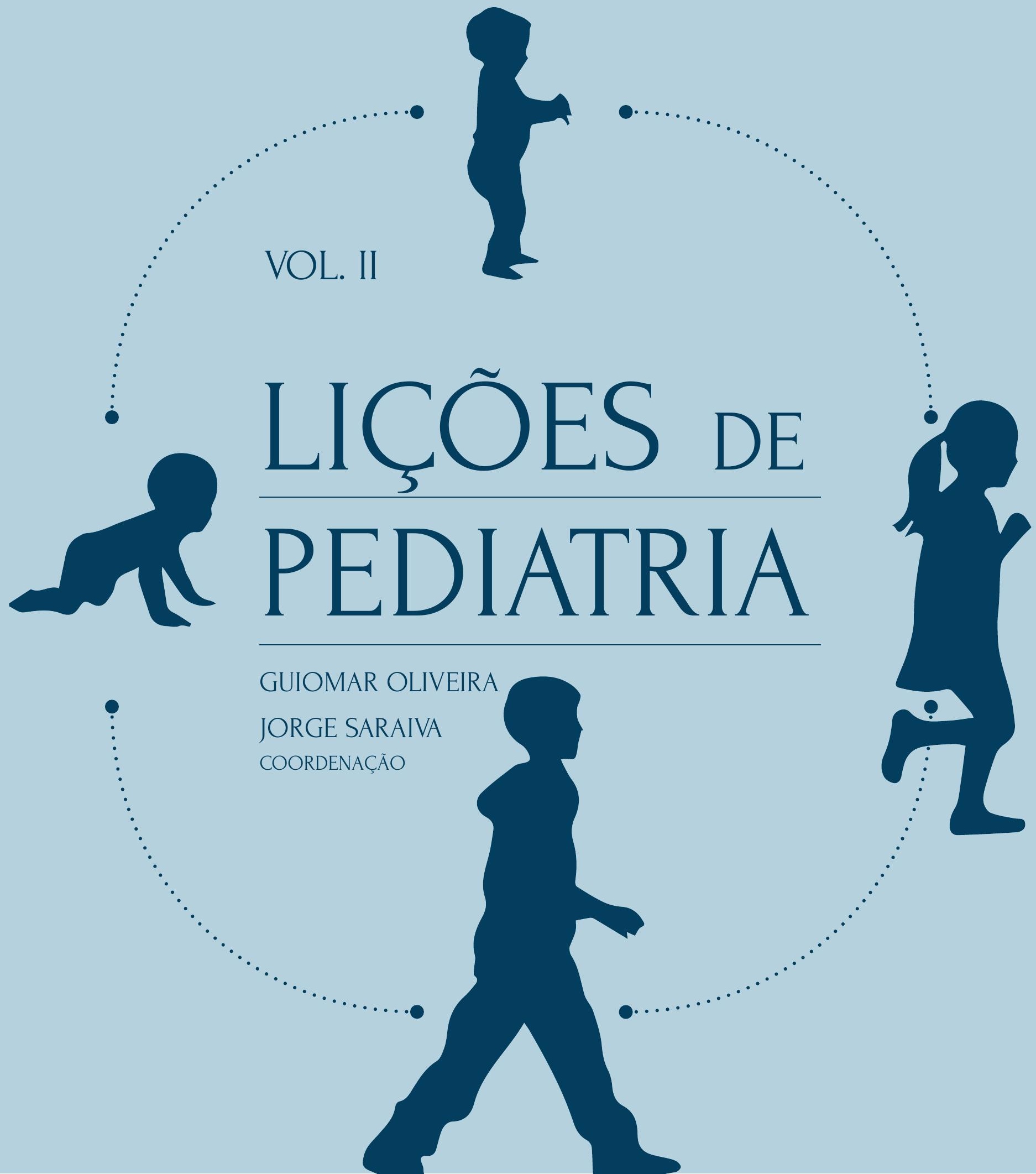


Capítulo 44.

Imunodeficiências Primárias quando suspeitar?

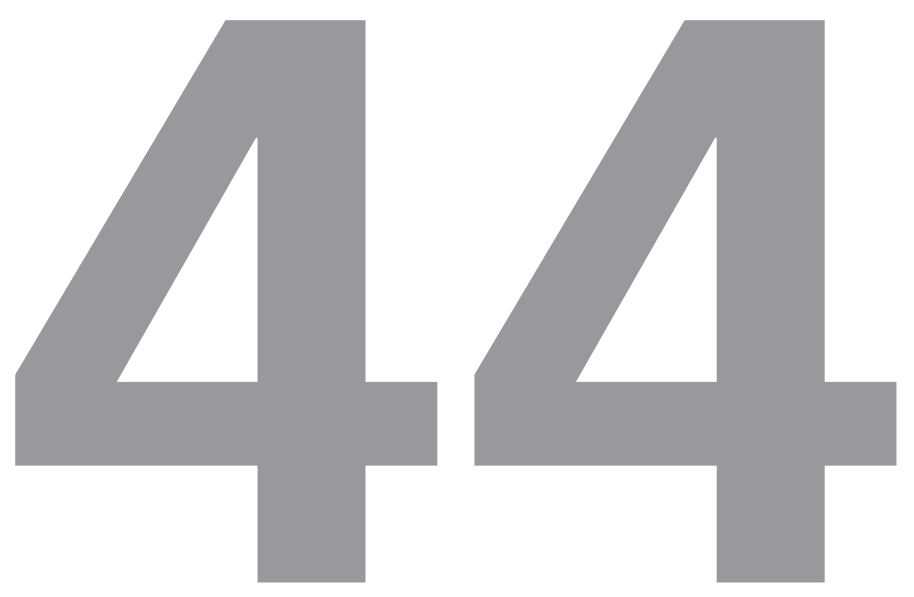

Sónia Lemos 
Página deixada propositamente em branco 


\subsection{CONTEXTO}

As imunodeficiências primárias (IDP) são um grupo de doenças que resulta de defeitos genéticos que afetam o desenvolvimento e/ou a função de componentes do sistema imunológico. A maioria é monogénica, herdada de forma autossómica recessiva, autossómica dominante ou recessiva ligada ao cromossoma X. Inicialmente apontadas como raras, nas últimas décadas o número identificado tem vindo a aumentar. A primeira IDP foi identificada há cerca de 60 anos e hoje estão descritas aproximadamente 200 formas diferentes. Embora a maioria seja rara, em conjunto afeta um em cada 2.000 nados vivos, variando entre 1/500 na deficiência seletiva de imunoglobulina (Ig)A (a IDP mais frequente mas muitas vezes assintomática) a 1/50.000 para as imunodeficiências combinadas graves ou Severe Combined Immunodeficiency (SCID).

\subsection{DESCRIÇÃO DO TEMA}

Atualmente as IDP estão divididas em oito grupos de acordo com o(s) componente(s) do sistema imunológico afetado(s):

1.Imunodeficiências combinadas de linfócitos B e linfócitos $\mathrm{T}$.

2.Deficiências de anticorpo.

3.Imunodesregulação.

4.Deficiências do complemento.

5.Deficiências da imunidade inata.

6.Deficiência de fagócitos.

7.Síndromes bem definidos com imunodeficiência.

8.Síndromes auto inflamatórios.

A figura 1 ilustra a distribuição e frequência dos diferentes grupos de IDP. O mais frequente é o grupo das deficiências de anticorpos, que compreende aproximadamente metade dos casos.

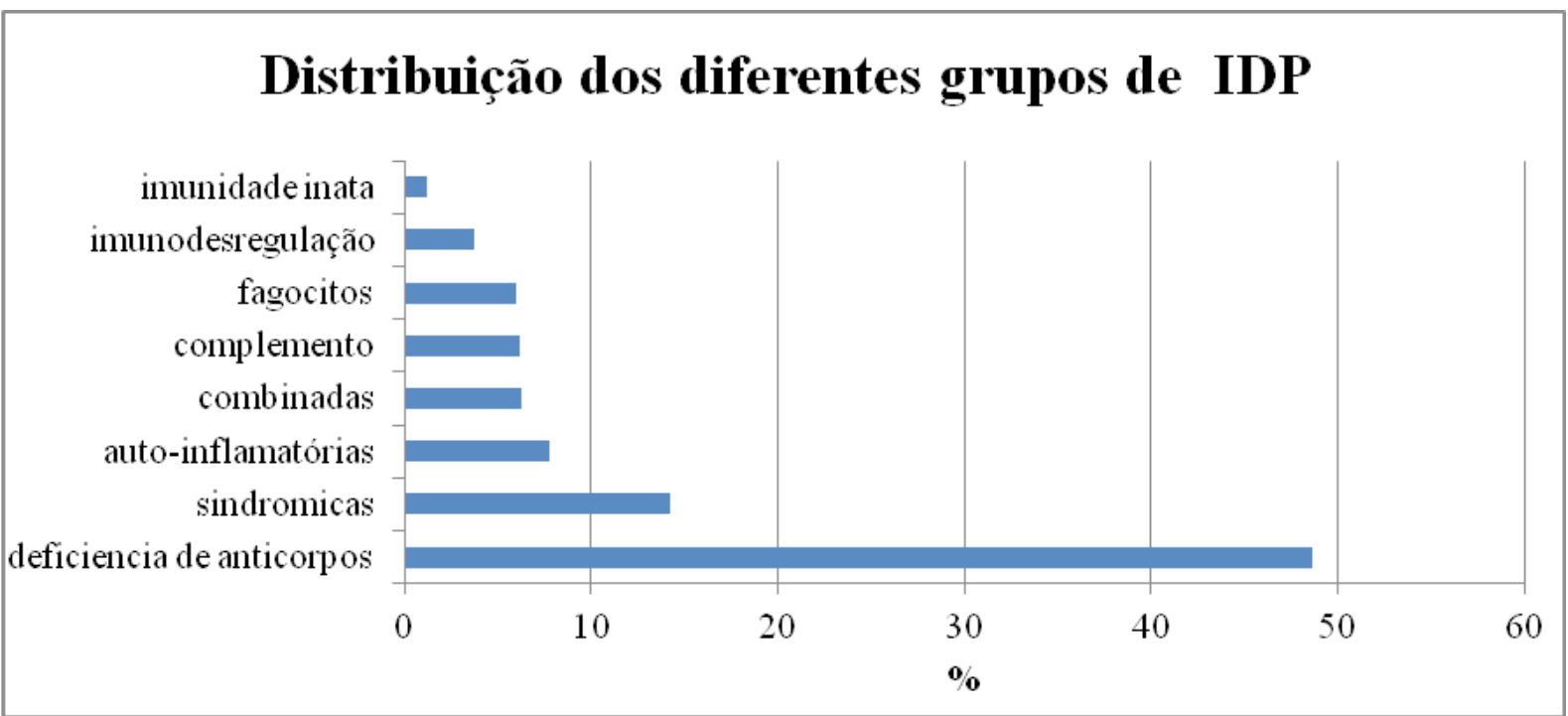

Figura 1. Distribuição e frequência das IDP por oito grupos. European Society for Immunodeficiencies registry 2010. 
Embora haja padrões clínicos mais específicos de cada grupo de IDP, a apresentação clínica é muito variável e ocorre grande sobreposição entre eles. Por exemplo: infeções de pele, abcessos profundos ou adenites por Staphylococcus aureus, Serratia marcescens, Burkhoderia cepacia, Nocardia sp, Candida e Aspergillus são as apresentações mais comuns das deficiências de fagócitos. Já as infeções respiratórias altas de repetição por bactérias capsuladas com início depois dos seis meses são características do grupo das IDP com deficiência de anticorpos.

As IDP causam grande morbilidade e algumas, como os SCIDs, evoluem inexoravelmente para a morte no primeiro ano de vida se não tratadas rapidamente com transplante de células hematopoiéticas pluripotenciais de medula óssea ou de cordão umbilical. O diagnóstico precoce de IDP é por isso essencial.
A grande etapa para o diagnóstico de uma IDP, não é tanto reconhecer os padrões clínicos caraterísticos de cada grupo, mas antes, conhecer sinais que devem alertar para a possibilidade de estarmos na presença de uma criança com IDP.

A grande maioria dos pacientes com IDP tem infeções graves ou de repetição, contudo estes não são os únicos sinais que devem sugerir a investigação de IDP.

Deve suspeitar-se de IDP na criança ou adolescente que apresente:

1. Suscetibilidade a infeções.

2. Fenómenos autoimunes.

3. Reações alérgicas graves.

4. Reações inflamatórias exageradas.

5. Neoplasias hematológicas (leucemias e linfomas).

\begin{tabular}{|l|ll|}
\hline $\begin{array}{l}\text { 1-Manifestações } \\
\text { clínicas }\end{array}$ & a. & Infeção que se enquadre no anagrama PeRIGOS (ver à frente) \\
& b. & $\begin{array}{l}\text { Má progressão ponderal/diarreia persistente } \\
\text { Ciabetes mellitus tipo 1 ou outra doença autoimune } \\
\text { e/ou inflamatória no primeiro ano de vida }\end{array}$ \\
& d. & $\begin{array}{l}\text { Quadro de sepsis na ausência de infeção bacteriana } \\
\text { e. }\end{array}$ \\
f. & Cardiopatias congénitas associadas a hipocalcémia \\
& g. & Atraso na queda do cordão umbiliçal (além de catorze dias) \\
\hline 2-História familiar & h. & Familiares com IDP confirmada ou suspeita \\
& i. & Presença de consanguinidade \\
\hline 3-Exame objetivo & j. & Tamanho de órgãos linfoides \\
& k. & Manifestações dermatológicas \\
& I. & Dismorfismos faciais e microcefalia \\
m. & Manifestações orais/dentárias \\
\hline 4-Exames & n. & Ausência de sombra tímica na radiografia do tórax \\
complementares & o. & Linfopenia ou outra citopenia persistentes \\
& p. & Leucocitose persistente \\
\hline
\end{tabular}


Conhecer os sinais de alerta de IDP é essencial para salvar vidas e/ou reduzir a morbilidade. Em 1993 foram publicados pela primeira vez os dez sinais de alerta para IDP. Desde então o número de IDP expandiu-se imenso e com ele o espetro de manifestações clínicas. Apesar disso, evidências recentes demonstram que com base nestes dez sinais, um em cada cinco doentes com IDP não seria diagnosticado, sendo agora estes dez sinais considerados uma "relíquia do passado".

Encontram-se sinais de alerta de IDP na história médica, na história familiar, no exame físico e em exames complementares de diagnóstico tão simples como um hemograma e uma radiografia do tórax (quadro 1).

\subsubsection{Manifestações clínicas}

a) Infeção que se enquadre no anagrama PeRIGOS

Grande suscetibilidade a infeções é a caraterística mais reconhecida das IDP. Numa criança/ adolescente com infeções frequentes, uma pista para a causa das infeções é o número de locais afetados. Infeções repetidas no mesmo local (i.e. pneumonias frequentes) sugerem um problema de órgão (anatómico, estrutural...como a fibrose quística) enquanto infeções em diversos locais (pneumonias e otites frequentes) são mais sugestivas de um processo mais sistémico como a IDP.

O anagrama PeRIGOS reúne as características das infeções que devem alertar para IDP:

Pe - Persistente;

R - Recorrente;

I - Imunização (vacinas);

G - Grave;

O - Oportunista;

S - Sequelas.

\section{Persistente}

qualquer infeção cuja evolução não é a esperada (i.e. bronquiolite a VSR) ou que persiste apesar de tratamento adequado.

\section{Recorrente}

infeção que após remissão, reaparece.

\section{Imunização}

neste caso existem duas situações:

\section{i) infeção após vacina viva atenuada -} em imunocompetentes, os agentes das vacinas vivas atenuadas não proliferam ao ponto de causar doença. Quando tal acontece, significa que existe uma grande fragilidade do sistema imunológico. Exemplos são a BCGite disseminada após vacina do BCG, o sarampo após a vacina do sarampo, a poliomielite ou a gastroenterite grave, após a vacina oral para a poliomielite ou rotavírus, respetivamente;

ii) falência vacinal com vacinas inativadas - nestes casos o recetor da vacina não se infeta com o agente vacinal, porque este é inativado, mas a infeção decorre do encontro com o microrganismo no meio ambiente. O doente foi incapaz de produzir anticorpos, o que também significa a existência de uma falha no sistema imunológico. Um exemplo é a pneumonia pneumocócica com um serotipo vacinal em criança/adolescente que completou o esquema vacinal da vacina conjugada antipneumocócica (Prevenar $^{\mathrm{R}}$ ). 
Grave

Uma única infeção mas grave é também um sinal de alerta de IDP.

\section{Oportunista:}

Microrganismos oportunistas são microrganismos muito pouco virulentos e como tal incapazes de causar doença em imunocompetentes. Uma infeção por um microrganismo oportunista é sempre um sinal de alerta para IDP. Exemplos são as infeções por Pneumocystis jirovecci, Aspergillus, Burkholderia cepacia ou infeções invasivas por Cândida. Neste caso, esperar por segunda infeção para considerar IDP pode ser fatal.

\section{Sequelas}

Infeções que deixem lesões (i.e. bronquiectasias, pneumatoceles) na ausência de um problema estrutural ou anatómico, devem também sugerir uma IDP.

b) Má progressão

ponderal/diarreia

persistente

Diarreia crónica grave, intratável, associada a má progressão ponderal é um sinal de alerta de IDP. A diarreia pode ser de causa infeciosa, auto-imune ou inflamatória. Nos primeiros três a quatro meses de vida, é uma manifestação comum de dois tipos de imunodeficiências muito graves: os SCIDs e a IPEX (imunodesregulação, poliendocrinopatia, enteropatia ligada ao cromossoma $\mathbf{X}$ ). O transplante de células hematopoiéticas pluripotenciais é o único tratamento. Na sua ausência as crianças morrem antes do primeiro ano de vida. c) Diabetes mellitus tipo 1 ou outra doença autoimune e/ou inflamatória

Autoimunidade é uma caraterística precoce de IDP com imunodesregulação. O IPEX é um exemplo. É caraterizado pela tríade de enteropatia (diarreia), diabetes mellitus tipo I e eczema grave tipicamente em doentes do sexo masculino nos primeiros meses de vida. Neste caso, anticorpos antienterócitos causam a enteropatia autoimune responsável pela caraterística diarreia aquosa grave. Anticorpos anti células de ilhéus pancreáticos ou anti insulina causam diabetes mellitus tipo I. Apesar de alguns doentes também apresentarem infeções graves, as manifestações autoimunes predominam. O IPEX é fatal se não for reconhecido.

\section{d) Quadro de sépsis na ausência de infeção bacteriana}

Sépsis é tipicamente causada por bactérias, fungos ou vírus. Quadro de sépsis sem identificação de infeção bacteriana é um sinal de alerta para IDP. Exemplo de IDP que se apresenta com quadro de "sepsis-like" é a linfohistiocitose hemafagocítica familiar.

\section{e) Cardiopatias congénitas} associadas a hipocalcémia

Cardiopatias congénitas (especialmente anomalias conotruncais) se associadas a hipocalcémia sugerem síndrome de microdeleção no braço longo do cromossoma 22 (22q11.2). A tríade clássica que o carateriza é: anomalias cardíacas conotruncais, hipoplasia tímica e hipocalcémia (resultante da hipoplasia das paratiroides). A hipoplasia tímica causa defeitos nos linfócitos T de gravidade variável, $1 \%$ dos doentes tem ausência 
completa do timo e imunodeficiência muito grave, os restantes têm imunodeficiência de menor gravidade.

\section{f) Neoplasias hematológicas}

em crianças pequenas

Neoplasia hematológica $(\mathrm{NH})$ deve evocar uma IDP se: idade inferior à esperada particularmente em caso de linfoma de Hodgkin e leucemia linfoblástica aguda de células T, presença de neoplasias simultâneas ou sequenciais ou $\mathrm{NH}$ associada a infeção pelo vírus Epstein Barr.

\subsubsection{História familiar}

Familiar com IDP (confirmada ou possível)

Sendo doenças genéticas, a maioria das vezes a criança com IDP tem ou teve um familiar com IDP pelo que a presença ou suspeita de IDP num familiar é considerado um dos sinais de alerta mais relevante e que mais se correlaciona com a presença de IDP.

\subsubsection{Exame objetivo}

\section{j) Tamanho de órgãos linfoides}

Quer a ausência quer o aumento excessivo de órgãos linfoides devem ser sinais de alerta. A ausência de amígdalas ou adenoides, ocorre na agamaglobulinemia ligada ao cromossoma $X$, uma IDP em que não há linfócitos B. A hipertrofia persistente dos gânglios é observada em IDP em que há defeitos da apoptose como no síndrome linfoproliferativo autoimune (ALPS).

\section{k) Manifestações dermatológicas}

Estão presentes em 40\% a 70\% dos doentes com IDP.
Telangiectasias oculo-cutâneas devem fazer suspeitar de ataxia telangiectasia.

\section{Albinismo oculo-cutâneo parcial ou total} é sugestivo de síndrome de Chediaki Higashi ou síndrome de Griscelli.

Eritrodermia (rubor difuso da pele que afeta mais de 90\% da superfície corporal) imediatamente após o nascimento associada a alopécia grave e má progressão estaturo ponderal, é imediatamente sugestiva de síndrome de Omenn, um tipo de SCID.

Eczema generalizado e resistente ao tratamento em crianças pequenas associado a elevados níveis de IgE total e IgEs específicas são sinais de alerta para síndrome de híper lgE e síndrome de Wiskott Aldrich.

Displasia da pele, unhas ou cabelo, surgem na disqueratose congénita, deficiência de NEMO. Além da suscetibilidade a infeções, estes doentes apresentam alterações de estruturas ectodérmicas como a pele, cabelo e dentes. Na deficiência de NEMO os doentes têm pele seca e escamosa, cabelo fino e escasso, ausência de glândulas sudoríparas e dentes cónicos (semeIhantes a dentes de tubarão). Na disqueratose congénita, apresentam unhas dismórficas, alterações da coloração da pele (aspeto reticulado) e leucoplaquia (placas brancas na língua).

\section{i) Dismorfismos faciais e microcefalia}

A associação de dismorfismos faciais (i.e. fácies em bico de pássaro), microcefalia e infeções recorrentes deve evocar uma IDP (síndrome de Nijmegen Breakage e Défice de ADN ligase IV).

m) Manifestações orais e dentárias

Leucoplaquia, úlceras aftosas recorrentes, dentes cónicos, ausência de queda de dentição 
de leite, associados a infeções, ocorrem em IDP como na disqueratose congénita, neutropenias, deficiência de NEMO, síndrome de Hiper-IgE, respetivamente.

\subsubsection{Exames complementares de diagnóstico}

A ausência de sombra tímica na radiografia do tórax é um sinal de alerta para IDP. Os lactentes apresentam timos tipicamente volumosos. Timos ausentes devem evocar sempre um SCID.

Linfopenia $(<3000 / \mathrm{ml})$ no primeiro trimestre de vida, é também um sinal de alerta de IDP e até prova em contrário um SCID.

Neutropenia (<1500 ml) persistente sugere neutropenia congénita.

Leucocitose persistente associada a queda tardia do cordão umbilical é caraterística das deficiências de adesão de leucócitos (LAD).

\subsection{FACTOS A RETER}

O diagnóstico precoce de IDP é essencial.

O tratamento precoce evita o curso por vezes fatal e melhora a qualidade de vida.

O diagnóstico precoce de IDP também é muito importante para aconselhamento genético e diagnóstico pré-natal.

Estas crianças devem ser estudadas e seguidas por equipas especializadas nestas patologias.

\section{Leitura complementar}

Cant A, Battersby A. "When to think of immunodeficiency?" Adv Exp Med Biol. 2013;764:167-77.

OSullivan MD, Cant AJ. The 10 warning signs: a time for a change? Curr Opin Allergy Clin Immunol. 2012 Dec;12(6):588-94.
Subbarayan A, Colarusso G, Hughes SM, Gennery AR, Slatter M, Cant AJ, Arkwright PD.Clinical features that identify children with primary immunodeficiency diseases. Pediatrics. 2011 May;127(5):810-6.

Lehman $\mathrm{H}$. Skin manifestations of primary immune deficiency. Clin Rev Allergy Immunol. 2014 Apr;46(2):112-9.

Szczawinska-Poplonyk A1, Gerreth K, Breborowicz A, Borysewicz-Lewicka M.

Oral manifestations of primary immune deficiencies in children. Oral Surg Oral Med Oral Pathol Oral Radiol Endod. 2009 Sep;108(3):e9-20. 